Abstract S5 Table 1 Yields for latent TB infection (as defined by a positive QuantiFERON assay) for different age-groups and at different screening thresholds. Those in bold represent current NICE guidance (note: NICE also recommends screening those aged 16-35 from SubSaharan countries which is not shown on this table for clarity)

\begin{tabular}{|c|c|c|c|c|}
\hline $\begin{array}{l}\text { Age group and } \\
\text { TB incidence } \\
\text { screening } \\
\text { threshold (per 100000) }\end{array}$ & $\begin{array}{l}\text { Number } \\
\text { tested }\end{array}$ & $\begin{array}{l}\text { Number } \\
\text { positive }\end{array}$ & $\begin{array}{l}\text { Yield at incidence } \\
\text { level, that is proportion } \\
\text { of those tested giving a } \\
\text { positive result (\%) }\end{array}$ & $\begin{array}{l}\% \text { of all LTBI } \\
\text { identified if } \\
\text { threshold set } \\
\text { at this level }\end{array}$ \\
\hline \multicolumn{5}{|l|}{$<16$ years } \\
\hline Screen all & 85 & 5 & 5.9 & 100 \\
\hline Screen $\geq 40$ & 77 & 5 & 6.5 & 100 \\
\hline Screen $\geq 100$ & 76 & 4 & 5.3 & 80 \\
\hline Screen $\geq 200$ & 31 & 3 & 9.7 & 60 \\
\hline Screen $\geq 300$ & 11 & 2 & 18.2 & 40 \\
\hline Screen $\geq 400$ & 6 & 2 & 33.3 & 40 \\
\hline Screen $\geq 500$ & 6 & 2 & 33.3 & 40 \\
\hline \multicolumn{5}{|l|}{$16-35$ years } \\
\hline Screen all & 678 & 142 & 20.9 & 100 \\
\hline Screen $\geq 40$ & 666 & 142 & 21.3 & 100 \\
\hline Screen $\geq 100$ & 597 & 136 & 22.8 & 95.8 \\
\hline Screen $\geq 200$ & 314 & 69 & 21.9 & 48.6 \\
\hline Screen $\geq 300$ & 106 & 30 & 28.3 & 21.1 \\
\hline Screen $\geq 400$ & 41 & 8 & 19.5 & 5.6 \\
\hline Screen $\geq 500$ & 34 & 7 & 20.6 & 4.9 \\
\hline \multicolumn{5}{|l|}{ Over 35 years } \\
\hline Screen all & 147 & 52 & 35.4 & 100 \\
\hline Screen $\geq 40$ & 145 & 52 & 35.9 & 100 \\
\hline Screen $\geq 100$ & 113 & 44 & 38.9 & 84.6 \\
\hline Screen $\geq 200$ & 81 & 33 & 40.7 & 63.5 \\
\hline Screen $\geq 300$ & 25 & 14 & 56.0 & 26.9 \\
\hline Screen $\geq 400$ & 10 & 7 & 70.0 & 13.5 \\
\hline Screen $\geq 500$ & 10 & 7 & 70.0 & 13.5 \\
\hline
\end{tabular}

Conclusions Immigrants have a high prevalence of LTBI but current NICE guidance detects only $38.2 \%$ of new entrants with LTBI. Given the high rates of reactivation of LTBI in new entrants, our findings suggest that consideration should be given to reducing the screening threshold to include those from the Indian Subcontinent (incidence 170/100 000) which would result in $67.8 \%$ of all LTBI cases being identified.

\section{S6 SENSITIVITY AND SPECIFICITY OF MOBILE DIGITAL CHEST RADIOGRAPHY FOR THE DIAGNOSIS OF ACTIVE PULMONARY TUBERCULOSIS. A COHORT STUDY IN HIGH RISK GROUPS IN LONDON}

doi:10.1136/thx.2010.150912.6

${ }^{1} \mathrm{R}$ W Aldridge, ${ }^{2} \mathrm{~A}$ Story, ${ }^{2} \mathrm{H}$ Stagg, ${ }^{1} \mathrm{M}$ Lipman, ${ }^{3} \mathrm{~J}$ Knight, ${ }^{3} \mathrm{D}$ Taubman, ${ }^{2} \mathrm{~K}$ Shaji, ${ }^{2} \mathrm{D}$ Quinn, ${ }^{2} \mathrm{~J}$ Watson, ${ }^{2} \mathrm{I}$ Abubakar, ${ }^{1} \mathrm{~A}$ Hayward. ${ }^{1} \mathrm{UCL}$, London, UK; ${ }^{2}$ Health Protection Agency, London, UK; ${ }^{3}$ Find and Treat TB Project, London, UK

Background Radiographic screening for pulmonary tuberculosis is used in high risk groups in many countries. There are no published reports of the sensitivity and specificity of this technique in an operational setting with high screening throughput. A Department of Health screening programme has used mobile digital chest radiography to identify pulmonary tuberculosis amongst homeless people, problem drug users and prisoners in London since April 2005. We aimed to use data from this programme and from national tuberculosis surveillance to establish the sensitivity and specificity of mobile digital X-ray screening for the identification of pulmonary tuberculosis.

Methods Data collected on those screened for the period March 2005 to March 2010 were collated. Abnormal radiographs were classified as: 1) suspected active tuberculosis; 2) signs of old inactive tuberculosis; 3) other suspicious findings that warrant further investigation (eg, possible cancer); 4) abnormal but no further investigation required; 5) normal. Demographic data from those screened were matched to the national tuberculosis surveillance database using probabilistic algorithms. Duplicates within the screening database (ie, persons having been screened more than once) were removed using the same algorithms. To calculate sensitivity and specificity all those who were referred with suspected active tuberculosis were classified as 'screen positive' with all others classified as 'screen negative'. The gold standard comparator was a notification of pulmonary tuberculosis within the four months after screening. Non-pulmonary cases of tuberculosis were also excluded.

Results 39225 individuals were screened during the study period, $75 \%$ were male and the median age was 36 (IOR 27-45). 430 of those screened were referred with suspected active tuberculosis for further investigation. Matching of the screening data to surveillance data identified 44 screened individuals who were notified with pulmonary tuberculosis within 4 months of screening, 36 of these were screen positive. Based on these results, sensitivity was $82 \%$ (95\% CI 67.3 to $91.8 \%$ ) and specificity $99.3 \%$ (95\% CI 99.1 to $99.3 \%$ ) (see Abstract S6 Table 1).

Abstract S6 Table 1 Screened cases with suspected active pulmonary TB compared to gold standard (notification of pulmonary tuberculosis within 4 months of screening)

\begin{tabular}{llrrr}
\hline & & \multicolumn{2}{c}{ Gold standard } & \\
\cline { 3 - 5 } & & Positive & Negative & Total \\
\hline Screen result & Positive & 36 & 312 & 348 \\
& Negative & 8 & 38869 & 38877 \\
& Total & 44 & 39181 & 39225 \\
\hline
\end{tabular}

Conclusion High throughput mobile digital radiographic screening for pulmonary tuberculosis has high sensitivity and specificity in high risk groups and should be considered as a key tool for active case finding in these populations.

\section{Economics and the burden of respiratory disease}

\section{S7 ANNUAL TRENDS IN ASTHMA EMERGENCY ATTENDANCE,} HOSPITAL ADMISSION AND READMISSION

doi:10.1136/thx.2010.150912.7

V Kuan, S J Quantrill. Department of Respiratory Medicine, Whipps Cross University Hospital, London, UK

Introduction and Objectives Recent government initiatives rooting care of chronic conditions in primary care settings with particular emphasis on reducing hospital use require on-going collection of high-quality data. However, in most Trusts this data are not systematically reported. Data around readmissions have recently become a priority issue with proposals to penalise secondary care Trusts with high readmission rates.

Methods Asthma emergency attendances and reattendances to our Trust from 2003/4 to 2009/10 and hospital admissions and readmissions from 2001/2 to 2009/10 were obtained from Symphony and Patient Administration System (PAS). For hospital admissions discharge coding was used to identify cases.

Results 8155 emergency attendances were recorded over the 7 year period between 2003/4 and 2009/10, of which 4691 were adult ( $\geq 18$ years) and 3464 children ( $<18$ years). During this time, 2927 patients out of 4479 (65\%) attended just once. Emergency 


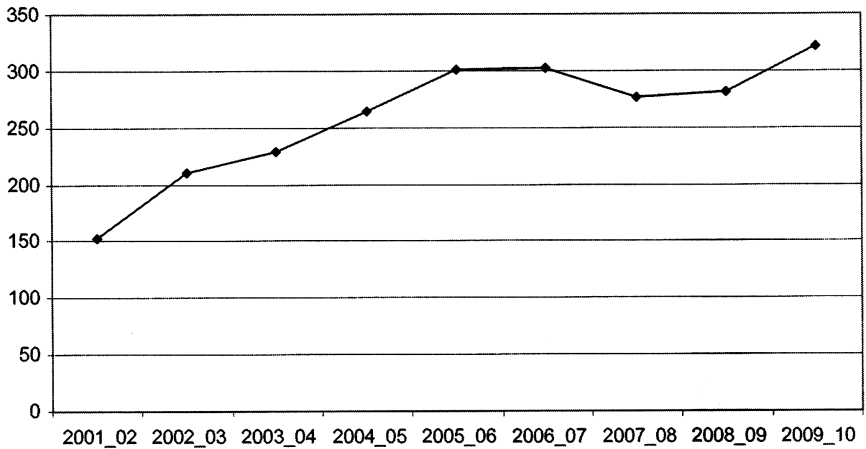

Abstract S7 Figure 1 Number of adult asthma admissions at Whipps Cross Hospital.

attendances were stable for children ranging from 442 in 2003/4 to 455 in 2008/9, but rose sharply to 652 in 2009/10. Adult emergency attendances decreased from 666 in 2003/4 to 512 in 2008/9, but also rose sharply in 2009/10 to 790 . Emergency adult reattendances for 0-28 days, 0-90 days and 0-365 days fell from 85, 128 and 227, respectively in 2003/4 to 38,64 and 142 in 2008/9. From 2001/2 to 2009/10, there were 3707(2341 adult, 1366 children) hospital asthma admissions. Out of 1599 adult patients over this period, 1225 had just one admission. Admissions rose from 98 to 191 for children and 153 to 322 for adults from 2001/2 to 2009/10. Hospital adult readmissions have varied, ranging from 5(2001/2) to 16(2008/9) for $0-28$ days, $14(2003 / 4)$ to $35(2005 / 6)$ for $0-90$ days and 35 $(2002 / 3)$ to $68(2005 / 6)$ for $0-365$ days. Mean length of stay fell from 5.80 days in 2001/2 to 3.88 days in 2009/10.

Conclusions Large numbers of patients attend our emergency department for acute asthma. Admissions for acute asthma have risen markedly, more than doubling over 9 years. Numbers of readmissions within 28 days are relatively small, but the readmission rate within one year is relatively high at $22.70 \%(2008 / 9)$. These figures have important implications for resource allocation and training across the primary/secondary care divide.

\section{S8 THE NATIONAL COPD RESOURCES AND OUTCOMES PROJECT (NCROP): ACTION PLAN ACHIEVEMENT SINCE 2007}

doi:10.1136/thx.2010.150912.8

${ }^{1} \mathrm{~J} F$ O'Reilly, ${ }^{2} \mathrm{~N}$ A Pursey, ${ }^{2,3} \mathrm{C} \mathrm{M}$ Roberts, ${ }^{2,4} \mathrm{R}$ A Stone. ${ }^{1}$ Aintree University Hospital, Liverpool, UK; ${ }^{2}$ Clinical Standards Department, Royal College of Physicians, London, UK; ${ }^{3}$ Barts and the London School of Medicine and Dentistry, Queen Mary University of London, London, UK; ${ }^{4}$ Taunton and Somerset NHS Foundation Trust, Taunton, UK

Introduction and Objectives In 2007, 100 acute respiratory units participated in the NCROP, a randomised controlled study to assess whether reciprocal peer review could facilitate service improvement. We identified themes in desired improvements and evaluated success in meeting action plan aims.

Methods Units were paired and randomised into intervention or control arms (54:46). Intervention teams undertook reciprocal peer review in 2007 and documented action plans for service improvement. In 2010, intervention units self-assessed their progress in achieving action plans. Qualitative responses were analysed using a grouped themes approach to derive action plan themes.

Results Data were received from 41 of 54 intervention units (76\%). The Abstract S8 Table 1 shows the distribution of themes and action plan outcomes.
Abstract S8 Table 1

\begin{tabular}{|c|c|c|c|c|c|}
\hline Action Plan theme & $\begin{array}{l}\text { Number } \\
n\end{array}$ & $\begin{array}{l}\text { Met in full } \\
n(\%)\end{array}$ & $\begin{array}{l}\text { Partially met } \\
\text { n }(\%)\end{array}$ & $\begin{array}{l}\text { Not met } \\
n(\%)\end{array}$ & $\begin{array}{l}\text { Not recorded } \\
\text { n }(\%)\end{array}$ \\
\hline $\begin{array}{l}\text { Multi-disciplinary team } \\
\text { development }\end{array}$ & 41 & $13(32)$ & $21(51)$ & \begin{tabular}{|ll}
6 & $(15)$
\end{tabular} & $1 \quad(2)$ \\
\hline Non Invasive Ventilation & 32 & $11 \quad(34)$ & $13(41)$ & $7(22)$ & (3) \\
\hline Pulmonary Rehabilitation & 26 & $10 \quad(38)$ & $10 \quad(38)$ & $5(19)$ & (4) \\
\hline Domiciliary oxygen & 24 & $12(50)$ & $7(29)$ & $4(17)$ & 1 (4) \\
\hline Early Discharge & 21 & $7 \quad(33.3)$ & $9(43)$ & $4(19)$ & $\begin{array}{ll}1 & (5) \\
\end{array}$ \\
\hline Palliative care & 12 & $2(17)$ & $8(66.6)$ & $1(8)$ & $1 \quad(8)$ \\
\hline Clinical Audit & 7 & $1 \quad(14)$ & $3(43)$ & 1 (14) & $2(29)$ \\
\hline Respiratory Ward & 4 & $2 \quad(50)$ & 0 & $2(50)$ & 0 \\
\hline Guideline implementation & 3 & $1 \quad(33.3)$ & $1(33.3)$ & 0 & $1(33.3)$ \\
\hline IT database & 2 & 0 & $1(50)$ & $1(50)$ & 0 \\
\hline Patient Education & 1 & 0 & 0 & $1(100)$ & 0 \\
\hline
\end{tabular}

Conclusions Action plan themes related predominantly to development of multi-disciplinary teams across primary and secondary care and to specialist service provision. Most aims were fully achieved in a third of units and partially achieved in a similar number. Palliative care plans were less prevalent although at least partially successful in two thirds. Overall change was greater than in the 1 year assessment of the NCROP audit $2008 .^{1}$

\section{REFERENCE}

1. Roberts CM, Stone RA, Buckingham RJ, et al. A randomised trial of peer review: the UK National Chronic Obstructive Pulmonary Disease Resources and Outcomes Project. Clinical Medicine 2010;10:223-7.

\section{S9 FEASIBILITY OF ESTABLISHING A REGIONAL WEANING UNIT IN SCOTLAND: MODELLING RESOURCE IMPLICATIONS AND COSTS}

doi:10.1136/thx.2010.150912.9

${ }^{1} \mathrm{~N}$ I Lone, ${ }^{2} \mathrm{D}$ Sorensen, ${ }^{1} \mathrm{~T} S \mathrm{~S}$ Walsh. ${ }^{1}$ University of Edinburgh, Edinburgh, UK; ${ }^{2} \mathrm{NHS}$ Lothian, Edinburgh, UK

Introduction Intensive care (ICU) admission is usually mandatory for patients requiring mechanical ventilation (MV). A proportion of patients require prolonged $\mathrm{MV}(\mathrm{PMV})$. In other countries, specialised weaning units allow stable PMV patients to be discharged from the ICU. These units offer cost savings because of lower staff-to-patient ratios. A recent report of UK ICU services recommended that hospitals review the need for specialised weaning centres locally

Aims To assess the feasibility of establishing a weaning unit in a Scottish health board region and to model the potential impact on ICU services.

Methods All admissions to the three adult ICUs in our health board requiring PMV ( $\geq 21$ days MV) during a 2-year period (2005-2006) were extracted from the Scottish Intensive Care Audit Group database. Four hypothetical weaning units were modelled using different admission criteria, ranging from Unit-A, which required a prolonged period of stability prior to transfer from ICU to the weaning unit (7 days free of both cardiovascular support (CVS) and renal replacement therapy), to Unit-D (2 days free of CVS only). The date of eligibility for each PMV patient for each unit was determined. We used remaining length of stay (LOS) in ICU after eligibility to calculate occupancy rate, refusal rate and net cost saving, varying unit capacity from 1 to 8 beds

Results During 2005-2006, 126 patients required PMV. Of these, the number eligible for transfer to a weaning unit varied from 101 (Unit-A) to 117 (Unit-D). Mean ICU LOS after reaching eligibility varied from 14.9 to 15.3 days. Occupancy rates for Unit-A ranged from $90.8 \%$ to $25.5 \%$ (1-bed to 8-bed unit) and for Unit-D from $93.3 \%$ to $30.5 \%$. Refusal rates for Unit-A ranged from $88.1 \%$ to $0 \%$, and for Unit-D $92.3 \%$ to $0 \%$. The greatest cost saving was for Unit$\mathrm{D}$ with 3 beds ( $\$ 344025)$ (Abstract S9 Figure 1). 